\section{Effects of Dietary Sulfur Amino Acids and Glycine on Fecal Steroid Excre- tion in Hepatoma-bearing Rats}

\author{
Kenji IshiHara, Kazumi Yagasaki, \\ Naohisa Okushi and Ryuhei FunABIKI \\ Laboratory of Nutritional Physiochemistry, \\ Department of Applied Biological Science, \\ Tokyo Noko University, Fuchu, \\ Tokyo 183, Japan
}

Received August 24, 1990

\begin{abstract}
Abnormalities in serum lipoprotein profiles have been reported in cancer patients. ${ }^{1)}$ Donryu rats subcutaneously implanted with an ascites hepatoma line of AH109A cells revealed a remarkable increase in very-low-density lipoprotein + low-density lipoprotein (VLDL + LDL)-cholesterol (Ch) and a decrease in high-density lipoprotein. (HDL)-Ch. ${ }^{2)}$ This AH109A-induced abnormality in serum lipoprotein profiles has been reported to be improved by dietary additions of $1.2 \%$ cystine (Cys) alone, $1.2 \%$ methionine (Met) alone and $1.2 \%$ Met and $2.5 \%$ glycine (Gly) in combination to a $20 \%$ casein diet, although no effect was observed in the case of Gly alone. ${ }^{3)}$ The concomitant addition of Met and Gly improved the AH109A-induced decrease in fecal bile acid excretion, ${ }^{4}$, but exerted no influence on either $\mathrm{Ch}$ synthesis in the liver or Ch absorption from the intestine. ${ }^{5)}$ The present study was attempted to determine which of the two amino acids, Met or Gly, is responsible for the stimulatory action of Met and Gly in combination on the fecal bile acid excretion
\end{abstract}

observed in AH109A-bearing rats. ${ }^{4)}$ At the same time, the effects of Cys and taurine (Tau) on fecal steroid excretions were also studied in AH109A-bearing rats, since both Cys and Tau are metabolites of Met and reported to stimulate bile acid synthesis in Hep $\mathrm{G} 2$ cells. ${ }^{6}$

Male Donryu rats (6 weeks of age, Nippon Rats, Saitama) were divided into six groups. Five groups (the tumor-bearing groups) were subcutaneously implanted with AH109A cells $\left(1 \times 10^{6}\right.$ cells/rat $)$, and one group was sham-implanted with phosphate-buffered saline as previously described. ${ }^{2)}$ The tumor-bearing groups were fed ad libitum with a $20 \%$ casein diet (control), the $20 \%$ casein diet being supplemented with either $1.2 \%$ L-Met, ${ }^{31}$ $1.2 \%$ L-Cys,${ }^{3)} 1.2 \%$ Tau ${ }^{7)}$ or $2.5 \%$ Gly. ${ }^{3 !}$ The tumor-free rats were fed with the $20 \%$ casein diet as a normal group, the composition of the $20 \%$ casein diet being the same as described before, ${ }^{4)}$ and amino acids being added to the diet at the expense of starch. Feces were collected individualiy for 2 days between the 12th and 14th days after implantation. Neutral and acidic steroids were extracted from the feces according to the method of Yamanaka et al. ${ }^{8)}$ Fecal acidic steroids (bile acids) were measured by a total bile acid-test kit (Wako Pure Chemical Industries, Osaka). ${ }^{4}$ Fecal neutral steroids were determined by a cholesterol C-test kit (Wako Pure Chemical Industries, Osaka). ${ }^{4)}$

The fecal neutral steroid and bile acid excretions are shown in Table I. The fecal excretion of bile acids was significantly reduced in the tumor-bearing groups, this confirming our previous results. ${ }^{4)}$ The tumor-induced decrease in bile acid excretion was significantly improved by Met or Cys supplementation, while Tau and Gly exerted no influence on fecal bile acid excretion, although Gly weakly improved it. Fecal neutral steroids were significantly lower in the tumor-bearing groups than in the normal group, and did not change in the amino acidsupplemented groups.

These present data suggest that the stimulatory action

Table I. Effects of Additions of Sulfur Amino Acids and Glycine, to a $20 \%$ Casein (20C) Diet on Fecal Steroid Excretion

\begin{tabular}{|c|c|c|c|c|}
\hline \multirow{3}{*}{ Diet } & \multirow{3}{*}{ Hepatoma } & \multicolumn{3}{|c|}{ Fecal excretion } \\
\hline & & Dry wt. & Neutral steroid & Bile acid \\
\hline & & ( $\mathrm{g} / \mathrm{rat} / 2$ days) & \multicolumn{2}{|c|}{ ( $\mu \mathrm{mol} / \mathrm{rat} / 2$ days) } \\
\hline $20 \mathrm{C}$ (normal) & - & $1.73 \pm 0.24^{\mathrm{a}}$ & $21.2 \pm 2.9^{\mathrm{a}}$ & $25.6 \pm 5.7^{\mathrm{a}}$ \\
\hline $20 \mathrm{C}$ (control) & + & $0.65 \pm 0.07^{b}$ & $12.2 \pm 2.4^{b}$ & $13.2 \pm 2.3^{b}$ \\
\hline $20 \mathrm{C}+1.2 \mathrm{Met}$ & + & $0.72 \pm 0.06^{b}$ & $7.8 \pm 0.5^{b}$ & $26.6 \pm 1.3^{\mathrm{a}}$ \\
\hline $20 \mathrm{C}+1.2 \mathrm{Cys}$ & + & $0.84 \pm 0.14^{b}$ & $10.1 \pm 1.1^{\mathrm{b}}$ & $30.1 \pm 4.3^{\mathrm{a}}$ \\
\hline $20 \mathrm{C}+1.2 \mathrm{Tau}$ & + & $0.74 \pm 0.03^{b}$ & $13.2 \pm 1.9^{\mathrm{b}}$ & $17.4 \pm 1.3^{\mathrm{b}}$ \\
\hline $20 \mathrm{C}+2.5 \mathrm{Gly}$ & + & $0.95 \pm 0.21^{b}$ & $11.2 \pm 1.8^{b}$ & $20.8 \pm 3.2^{\mathrm{ab}}$ \\
\hline
\end{tabular}

Each value represents the mean of four (control) or five (others) rats \pm standard error. Values not sharing a common letter are significantly different at $p<0.05$ by Duncan's multiple-range test. 
of Met and Gly in combination on bile acid excretion into feces $^{4)}$ is mainly attributable to Met. From the present and previous findings, ${ }^{3-5)}$ it is also suggested that the dietary supplementation of either Met, Cys, or Met and Gly in combination is effective on AH109A-induced hypercholesterolemia, and that one of the hypocholesterolemic actions of these amino acids is at least partly explained by the stimulation of bile acid excretion into feces. Cholesterol $7 \alpha$-hydroxylase is known as a rate-limiting enzyme of bile acid biosynthesis. Kalles and Wikvall have reported that this enzyme activity was highly dependent on reduced sulfhydryl groups in a reconstituted system. ${ }^{93}$ Stephan et al., ${ }^{6)}$ using Hep G2 cells, showed that Tau and cysteine enhanced LDL receptor activity and bile acid synthesis, Tau stimulating them by sparing the consumption of cellular cysteine. Cysteine is a sulfhydryl group donor and a stimulator of Ch $7 \alpha$-hydroxylase. ${ }^{10)}$ Hence, in our case, the enhancing effect of dietary Met (a precursor of cysteine) and Cys on fecal bile acid excretion is considered to be attributable to the $\mathrm{Ch} 7 \alpha$-hydroxylase-stimulating action of intracellular sulfhydryl groups dependent on cysteine and/or glutathione whose constituent is cysteine. In Ch-loaded mice ${ }^{8)}$ and rats, ${ }^{11)}$ Tau has been reported to stimulate fecal bile acid excretion. In the present study, however, Tau did not stimulate it. There has been a report describing no effect of Tau on human subjects, ${ }^{12)}$ and Smith and Rossi showed high Tau contents in various tumor tissues. ${ }^{13}$ Provided this is true of the AH109A tumor tissue and that Tau discharges into the host liver via blood circulation, exogenous (or dietary supplemented) Tau may no longer show such a cysteine-sparing effect as described previously. ${ }^{6)}$ Measurements of the Tau content in the liver and solid hepatoma may clarify this aspect.

\section{References}

1) U. E. Nydegger and R. E. Butler, Cancer Res., 32, 1756 (1972).

2) T. Irikura, K. Takagi, K. Okada and K. Yagasaki, Lipids, 20, 420 (1985).

3) K. Yagasaki, M. Machida and R. Funabiki, J. Nutr. Sci. Vitaminol., 32, 643 (1986).

4) K. Yagasaki, M. Machida-Takehana and R. Funabiki, J. Nutr. Sci. Vitaminol., 36, 45 (1990).

5) K. Yagasaki, in "Absorption and Utilization of Amino Acids," Vol. II, ed. by M. Friedman, CRC Press, Fl., 1989, pp. 275-287.

6) Z. F. Stephan, S. Lindsey and K. C. Hayes, J. Biol. Chem., 262, 6069 (1987)

7) J. A. Jackson and M. J. Burns, Comp. Biochem. Physiol., 48A, 61 (1974).

8) Y. Yamanaka, K. Tsuji and T. Ichikawa, J. Nutr. Sci. Vitaminol, 32, 287 (1986).

9) I. Kalles and K. Wikvall, Biochem. Biophys. Res. Commun., 100, 1361 (198I).

10) H. Danielsson, I. Kalles and K. Wikvall, J. Biol. Chem., 259, 4258 (1984).

11) K. Sugiyama, A. Ohishi, Y. Ohnuma and K. Muramatsu, Agric. Biol. Chem., 53, 1647 (1989).

12) N. Tanno, S. Oikawa, M. Koizumi, Y. Fujii, S. Hori, N. Suzuki, E. Sakuma, H. Kotake, K. Nakai and T. Toyota, Tohoku J. Exp. Med., 159, 91 (1989).

13) L. C. Smith and F. M. Rossi, Proc. Soc. Exp. Biol. Med., 87, 643 (1954). 